\title{
Antecedentes Psicossociais e Organizacionais do Compartilhamento de Conhecimento no Ambiente de Trabalho
}

\author{
Psychosocial and Organizational Antecedents of Knowledge Sharing \\ in the Workplace
}

\section{RESUMO}

Objetivo: este artigo propõe e avalia um modelo causal sobre compartilhamento de conhecimento entre pares no ambiente de trabalho. $\mathrm{O}$ modelo proposto, integrado à Teoria do Comportamento Planejado, inclui fatores psicossociais (liderança transformacional, identificação com o grupo de trabalho, e entendimento compartilhado) e organizacionais (oportunidades e formalização de processos de compartilhamento de conhecimento) como antecedentes das atitudes do indivíduo, de sua percepção sobre normas subjetivas associadas a seu grupo e seu supervisor direto, e de sua intenção e comportamento efetivo de compartilhamento de conhecimento. Métodos: o modelo foi testado estatisticamente com técnicas de modelagem de equações estruturais, a partir de dados fornecidos por 131 funcionários da área de atendimento ao cliente de uma grande empresa brasileira de telecomunicacões. Resultados: os resultados indicam que os elementos psicossociais avaliados têm forte influência nas atitudes e práticas de compartilhamento de conhecimento entre pares. As hipóteses associadas ao controle comportamental não foram comprovadas. Além disso, a intencão de compartilhar conhecimento não parece ser afetada pelas normas subjetivas associadas ao supervisor direto do indivíduo, e sim apenas pelas relacionadas a seu grupo. Conclusões: a proximidade cognitiva entre os membros do grupo, refletida na percepcão do indivíduo de entendimento compartilhado com seu grupo de trabalho, foi um elemento importante na formação de atitudes favoráveis ao compartilhamento de conhecimento. Adicionalmente, indivíduos com maior identificação com o seu grupo tenderam a ter atitudes mais positivas em relação ao compartilhamento de seus conhecimentos. Essa atitude tende a ser mais positiva quando o supervisor direto do indivíduo adota um estilo de liderança mais transformacional. A influência dos líderes parece se estender desde a formação de uma cultura de troca de conhecimento no grupo e difusão de princípios que estimulam essa troca, até a viabilização de oportunidades por meio de uma gestão ativa da difusão de conhecimento nas equipes.

Palavras-chave: compartilhamento de conhecimento; Teoria do Comportamento Planejado; liderança transformacional; identificação; entendimento compartilhado.

Classificação JEL: J81, D20, D80.

Centro Universitário IBMEC, Mestrado Profissional em Administração, Rio de Janeiro, RJ, Brasil.

${ }^{2}$ Universidade do Estado do Rio de Janeiro, Rio de Janeiro, RJ, Brasil.

${ }^{3}$ Pontifícia Universidade Católica do Rio de Janeiro, IAG - Escola de Negócios, Rio de Janeiro, RJ, Brasil.

\section{ABSTRACT}

Objective: this paper proposes and evaluates a causal model to explain knowledge sharing among peers in the workplace. The proposed model, based on the Theory of Planned Behavior, includes psychosocial factors (transformational leadership, workgroup identification, and shared understanding) and organizational factors (knowledge sharing opportunities and formalization of knowledge sharing processes) as antecedents of individuals' attitudes, perception of subjective norms associated with their group and their direct supervisor, and intention and effective knowledge-sharing behavior. Methods: the model was statistically tested using structural equation modeling techniques with data provided by 131 customer service employees of a large Brazilian telecommunications company. Results: the results indicate that the psychosocial elements have a strong influence on knowledge sharing attitudes and practices. The hypotheses associated with behavioral control have not been confirmed. Moreover, the intention to share knowledge does not seem to be affected by the subjective norms associated with the individual's direct supervisor, but only by those related to their group. Conclusions: the cognitive proximity between group members, reflected in their perception of shared understanding, was an important element in the elicitation of attitudes favorable to knowledge sharing. Additionally, individuals with greater identification with their group tended to have more positive attitudes toward sharing their knowledge. This attitude tends to be more positive when the individual's direct supervisor adopts a more transformational leadership style. The influence of leaders seems to extend from the development of a culture of knowledge exchange and diffusion of principles that stimulate this exchange, to the creation of opportunities to share knowledge through the active management of knowledge diffusion in their teams.

Keywords: knowledge sharing; Theory of Planned Behavior; transformational leadership; identification; shared understanding.

Como citar: Moreno, V., Cavazotte, F., \& Dutra, J. P. (2020). Psychosocial and organizational antecedents of knowledge sharing in the workplace. Revista de Administração Contemporânea, 24(4), 283-299. https://doi.org/10.1590/1982-7849rac2020190239

Editor-chefe: Wesley Mendes-Da-Silva (Fundação Getulio Vargas, EAESP, Brasil) Pareceristas: José Rezende (Centro Universitário IBMEC, Brasil) [D Adriana Bruscato Bortoluzzo (INSPER, Brasil) [e

\# de revisores convidados até a decisão:

\begin{tabular}{|c|c|c|c|c|c|c|c|c|c|}
\hline & 1 & 2 & 3 & 4 & 5 & 6 & 7 & 8 & 9 \\
\hline $1^{a}$ rodada & (x) & 9 & (x) & (x) & $\stackrel{\varphi}{2}$ & & & & \\
\hline $2^{a}$ rodada & 2 & (x) & & & & & & & \\
\hline
\end{tabular}




\section{INTRODUÇÃO}

O conhecimento tem um papel crítico na geração de vantagem competitiva e na facilitação das relações de trabalho nas organizações (Alavi \& Leidner, 2001; Dewhurst, Hancock, \& Ellworth, 2013; Z. Wang, Wang, \& Liang, 2014). Composta por um conjunto de metodologias, ferramentas e técnicas, a Gestão do Conhecimento tem como objetivo principal a geração, aprimoramento, armazenamento, transferência, reutilização e proteção de conhecimentos nas organizações (Moreno \& Santos, 2012; Murray \& Peyrefitte, 2007). Porém, para que as empresas obtenham vantagem competitiva a partir dos conhecimentos que detêm, é necessário que estes sejam efetivamente compartilhados entre indivíduos, áreas e unidades de negócio (Murray \& Peyrefitte, 2007). Embora diversos autores tenham ressaltado a importância do compartilhamento de conhecimento (Alavi \& Leidner, 2001; Kang \& Kim, 2010; Levine \& Prietula, 2012), poucas pesquisas empíricas abordam a temática e seus condicionantes de forma ampla e integrada. Um melhor entendimento das dinâmicas do compartilhamento e seus principais antecedentes é necessário para orientar o desenvolvimento de programas e soluções efetivas para promover a difusão de conhecimento nas organizações (Levine \& Prietula, 2012).

Dado que compartilhar conhecimento é algo que se dá nas interações sociais, este estudo propõe que processos psicossociais são propulsores particularmente relevantes dessas trocas entre pares. Destaca-se aqui o papel desempenhado pela liderança e pelas identidades sociais em coletivos. Alguns autores sugerem que o comportamento dos líderes pode afetar o compartilhamento de conhecimento por parte de seus subordinados (Bradley, \& Liang, 2011; Le \& Lei, 2019; Xue, Zhang, Wang, \& Zhang, 2018). Porém, os mecanismos por meio dos quais essa influência ocorre ainda não foram elucidados do ponto de vista teóricoconceitual, nem testados empiricamente e de forma integrada com os conceitos e dinâmicas centrais já consolidadas na literatura sobre o compartilhamento de conhecimento (Donato, Hedler, \& Coelho Junior, 2017). Neste estudo, a Teoria do Comportamento Planejado (TCP) (Ajzen, 1991; 2012) é adotada como base conceitual para investigar as conexões entre a liderança e o compartilhamento de conhecimento em grupos de trabalho. $\mathrm{O}$ estudo explicita num modelo estrutural como o comportamento dos líderes atua sobre os diferentes construtos e processos definidos na TCP.

A pesquisa também contribui para o campo da Administração ao investigar o papel das identidades sociais no compartilhamento de conhecimento. A literatura sobre grupos e utilização de sistemas sugere que os vínculos entre indivíduos e coletivos variam em intensidade, e que o forte senso de pertencimento favorece a coesão, a adesão a normas sociais e a cooperação (DeSanctis \& Poole, 1997; van Dick, Grojean, Christ, \& Wieseke, 2006). Alguns estudos têm observado associações entre vínculos identitários e o compartilhamento de conhecimento em equipes (Liu \& Li, 2018). Autores que adotam a Visão Baseada em Conhecimento (Knowledge-Based View) em seus estudos (Carmeli, Atwater, \& Levi, 2011; Kogut \& Zander, 1996; Zhu, 2016) sugerem que a identificação com a organização facilita a comunicação e a coordenação, assim como o aprendizado de normas e procedimentos, contribuindo para o compartilhamento de conhecimentos e a geração de valor para o negócio. Assim, além da liderança como fator psicossocial, incluiu-se a identificação organizacional no modelo proposto, de forma a analisar o papel desses antecedentes psicossociais em conjunto com o de antecedentes organizacionais já discutidos na literatura. Dessa forma, o estudo contribui para a consolidação e integração de antecedentes psicossociais e organizacionais críticos que viabilizam trocas de saberes essenciais à criação e transformação de conhecimentos.

O modelo proposto foi testado com dados fornecidos por funcionários da área de atendimento ao cliente de uma empresa brasileira de grande porte, do setor de telecomunicações. A partir dele, identificouse um conjunto parcimonioso de fatores com maior influência nas dinâmicas de compartilhamento. Os resultados contribuem para o aperfeiçoamento de programas e práticas que visem promover a difusão de conhecimento em grupos e organizações.

\section{GESTÃO E COMPARTILHAMENTO DO CONHECIMENTO}

A Visão Baseada em Recursos (VBR) (Barney, 1991) propõe que a geração de vantagem competitiva tem por base recursos desenvolvidos e controlados pelas empresas. Segundo Grant (1996), o conhecimento é o recurso de maior relevância estratégica para as organizações. Ao contrário dos estoques financeiros, de recursos naturais e de mão-de-obra, o conhecimento é intangível e de valor econômico ainda difícil de compreender, classificar e medir.

Davenport e Prusak (1998), Probst, Raub e Romhart (2002) e Takeuchi e Nonaka (2008) ressaltam que o conhecimento é criado e transmitido pelos membros da organização por meios estruturados, tais como reuniões, acervos de melhores práticas, portais do conhecimento, e coaching e mentoring. Esses autores afirmam que a criação do conhecimento organizacional deve ser entendida como o processo que amplifica o alcance do conhecimento criado pelos indivíduos e o cristaliza no nível do grupo, por 
meio de diálogo, discussão, compartilhamento de experiências, e comunidades de prática.

A Gestão do Conhecimento (GC) pode ser entendida como um processo sistemático, articulado e intelectual, que busca gerar, armazenar, compartilhar, reutilizar e preservar o conhecimento organizacional (Moreno \& Santos, 2012; Murray \& Peyrefitte, 2007) para gerar vantagem competitiva (Stewart, 1998). De acordo com Davenport e Prusak (1998), cabe à GC desenvolver uma cultura que estimule a busca, o compartilhamento e a utilização do conhecimento, e uma estrutura de sistemas, tecnologias e redes de indivíduos que habilite a colaboração e a troca de experiências, informações e conhecimento. De forma similar, Takeuchi e Nonaka (2008) propõem que as organizações estabeleçam condições e processos adequados para o desenvolvimento $\mathrm{e}$ difusão tanto do conhecimento explícito, como do conhecimento tácito, numa dinâmica iterativa baseada em quatro mecanismos: (1) socialização, com foco no compartilhamento de conhecimento tácito; (2) externalização, com foco na transformação de conhecimento tácito em explícito; (3) combinação, com foco na associação e aplicação de conhecimentos explícitos; e (4) internalização, com foco na incorporação de conhecimento explícito em tácito.

Estudos sobre o compartilhamento de conhecimento têm por foco a movimentação do conhecimento através das fronteiras criadas por domínios especializados de conhecimento (Carlile \& Rebentisch, 2003). Liyanage, Elhang, Ballal e Li (2009), por exemplo, caracterizam o compartilhamento de conhecimento a partir de três elementos básicos: a fonte do conhecimento (ou origem), o destino do conhecimento (ou receptor), e o modo ou processo por meio do qual o compartilhamento se dá. O conceito de compartilhamento vai, portanto, além do nível do indivíduo, manifestando-se em níveis mais elevados de análise, como grupos, linhas de produtos ou departamentos (Argote \& Ingram, 2000).

O presente estudo aborda o compartilhamento de conhecimento no nível do indivíduo. Nesse contexto, o compartilhamento pode ser entendido como o processo pessoa-a-pessoa por meio do qual indivíduos partilham seus conhecimentos uns com os outros (Takeuchi \& Nonaka, 2008). Tal processo é crucial e inerente ao efetivo compartilhamento de conhecimento em níveis mais elevados de análise.

\section{DESENVOLVIMENTO DO MODELO PROPOSTO}

A Teoria do Comportamento Planejado (TCP) é um modelo cognitivo do comportamento humano que visa entender e prever como os indivíduos transformam suas intenções em comportamentos (Ajzen, 1991; 2012). O modelo proposto neste artigo parte das premissas da TCP. O elemento central no modelo de Ajzen é a intenção comportamental, ou seja, a motivação de um indivíduo para se comportar de uma determinada forma. Ela é entendida como precursora de ações humanas específicas, sendo reflexo de atitudes positivas em relação ao comportamento em questão. Pesquisas têm indicado que a intenção de realizar um comportamento é o indicador mais influente do comportamento propriamente dito (Ajzen, 2012). Dessa forma, propõe-se:

Hipótese 1: a intenção de um indivíduo de compartilhar seus conhecimentos com seus pares influencia positivamente seu comportamento de compartilhamento de conhecimento.

De acordo com Ajzen (1991; 2012), uma intenção comportamental se forma a partir de normas sociais subjetivas. Normas subjetivas são crenças do indivíduo de que outras pessoas em sua rede social desejam que ele/ela realize uma ação, isto é, sua percepção das pressões sociais para que tenha ou não um determinado comportamento. Estudos empíricos têm validado a influência das normas subjetivas na intenção de realizar comportamentos tão variados quanto a adoção de uma nova tecnologia, a realização de atividades físicas, e o uso de preservativos (Ajzen, 2012).

Num ambiente de trabalho onde se valoriza a aprendizagem contínua, os membros do grupo ou área da empresa compartilham percepções e expectativas de que a aprendizagem é uma parte importante da sua rotina de trabalho e de que o conhecimento é um elemento central, necessário e valorizado por grupos de referência, como pares e superiores (Correia, 2013; Donato et al., 2017; Santos \& Bastos, 2019; Sordi, Binotto, \& Ruviaro, 2014; Tracey, Tannenbaum, \& Kavanagh, 1995). Logo, pode-se assumir que, em tais ambientes, os membros da rede de relacionamento de um indivíduo tendem a manifestar a expectativa de que ele/ela se comporte de modo condizente com esses valores, inclusive compartilhando os seus conhecimentos com seus pares. Essas expectativas constituiriam, portanto, normas subjetivas associadas ao comportamento de compartilhamento de conhecimento, podendo variar em intensidade em função do grau em que o dado grupo social valoriza a aprendizagem contínua (Erden, Von Krogh, \& Kim, 2012). Assim, propõe-se:

Hipótese 2: a intensidade com que os pares de um indivíduo se mostram favoráveis à aprendizagem contínua influencia positivamente a intenção do indivíduo de compartilhar seus conhecimentos. 
Hipótese 3: a intensidade com que o superior hierárquico de um indivíduo se mostra favorável à aprendizagem contínua influencia positivamente a intenção do indivíduo de compartilhar seus conhecimentos.

As atitudes em relação a um comportamento são avaliações de uma pessoa em relação a tal ação e seus resultados prováveis (Ajzen, 1991; 2012). A atitude une o interesse em realizar determinado comportamento aos resultados prospectados, considerando a probabilidade subjetiva de que o comportamento produzirá esses resultados. A atitude em relação a um comportamento é um importante antecedente da intenção de se ter esse comportamento e da concretização do comportamento em si, inclusive no que tange ao compartilhamento de conhecimento (Bock, Zmud, Kim, \& Lee, 2005; Erden et al., 2012; S.S. Chen, Chuang, \& Chen, 2012; Tonet \& Paz, 2006). Assim, propõe-se:

Hipótese 4: a atitude favorável do indivíduo em relação ao compartilhamento de conhecimento influencia positivamente sua intenção de compartilhar seus conhecimentos.

Segundo a TCP, a intenção de realizar um comportamento e a realização do comportamento em si são influenciadas pela percepção do indivíduo de controle comportamental. Portanto, independentemente do quão favorável é a atitude de um indivíduo e da intensidade das normas subjetivas por ele percebidas, sua intenção de se comportar de uma determinada forma, assim como a concretização desse comportamento são atenuadas quando ele acredita que não dispõe de recursos ou oportunidades para agir desse modo (Ajzen, 1991; 2012). No ambiente organizacional, dois fatores contribuem para a formação da percepção do indivíduo de controle comportamental em relação ao comportamento de compartilhamento de conhecimento: (1) a existência de oportunidades ao longo de sua rotina de trabalho para compartilhar seus conhecimentos; e (2) a existência de um processo formalizado para se compartilhar conhecimentos com outros indivíduos.

Von Krogh, Ichijo e Nonaka (2000) definem como contextos capacitantes os espaços compartilhados nos quais ocorrem interações sociais que viabilizam elementos necessários aos processos de criação. O ambiente ideal é importante porque a criação de conhecimentos tem uma natureza fluida, e se dá nas oportunidades de interação entre pessoas. Em consonância com a TCP, estudos empíricos indicam que a inclusão de oportunidades para o compartilhamento de conhecimento na rotina de trabalho tem uma influência positiva na intenção do indivíduo de compartilhar conhecimento com seus pares (Barbosa, Monteiro, \& Freitas, 2012; Correia, 2013; Erden et al., 2012; Siemsen, Roth, \& Balasubramanian, 2008). Nesse contexto, o termo Oportunidade diz respeito à existência de canais, meios, e tempo que podem ser dedicados ao compartilhamento de conhecimento (Erden et al., 2012). Tonet e Paz (2006), no entanto, ressaltam que a oportunidade deve ir além do ato de compartilhar conhecimento, sendo também importante para o esclarecimento de dúvidas e a retificação dos conhecimentos já passados que ainda mereçam atenção. Portanto, propõe-se:

\begin{abstract}
Hipótese 5a: a existência de oportunidades para o compartilhamento de conhecimento no ambiente de trabalho está positivamente associada à intenção do indivíduo de compartilhar seus conhecimentos.
\end{abstract}

Hipótese 5b: a existência de oportunidades para o compartilhamento de conhecimento no ambiente de trabalho está positivamente associada ao compartilhamento de conhecimento pelo indivíduo.

Segundo Durcikova e Gray (2009), a transparência dos procedimentos operacionais é função do seu grau de formalização, documentação, detalhamento, revisão periódica, padronização e divulgação para todos os envolvidos. Processos formalizados são mais transparentes e percebidos como justos, porque estabelecem expectativas claras, convidam o envolvimento dos indivíduos, e fornecem explicações para o desenvolvimento das atividades e decisões. Assim, a existência de processos formalizados para o compartilhamento de conhecimento entre pares deve aumentar a percepção dos envolvidos de que há meios e recursos apropriados disponíveis para apoiar o comportamento de compartilhamento (Barbosa et al., 2012; Marjanovic \& Freeze, 2012; Santos \& Bastos, 2019; Sordi et al., 2014; Tonet \& Paz, 2006). Logo, propõe-se:

Hipótese 6a: a existência de processos e procedimentos operacionais formalizados para o compartilhamento de conhecimento na organização influencia positivamente a intenção do indivíduo de compartilhar seus conhecimentos.

Hipótese 6b: a existência de processos e procedimentos operacionais formalizados para o compartilhamento de conhecimento na organização influencia positivamente o compartilhamento de conhecimento pelo indivíduo.

No modelo proposto, são integrados à TCP três fatores psicossociais que devem influenciar o desenvolvimento de normas subjetivas e atitudes 
favoráveis ao compartilhamento de conhecimento no nível individual: (1) entendimento compartilhado, (2) identificação com o grupo, e (3) liderança transformacional.

Nelson e Cooprider (1996) e Gerwin e Moffat (1997) definem entendimento compartilhado como o grau em que crenças sobre o trabalho (ex.: normas, filosofia, resolução de problemas e experiência de trabalho) de uma díade são semelhantes. O entendimento compartilhado é um entendimento natural e evidente, dado de antemão, e que confere organicidade à coletividade, mantendo as pessoas unidas a despeito de todos os fatores que as separam. Estudos empíricos verificaram que heurísticas semelhantes e perspectivas e experiências compartilhadas entre pares são importantes antecedentes de compartilhamento de conhecimento (Ghobadi, 2015; Hong \& Vai, 2008; Rosenkranz, Vranešić, \& Holten, 2014). Por conseguinte, propõe-se:

Hipótese 7: a percepção do indivíduo de que há entendimento compartilhado com seus pares influencia positivamente sua atitude em relação ao compartilhamento de conhecimento.

DeSanctis e Poole (1997) afirmam que uma "representação cognitiva compartilhada ou senso de coletividade" (p. 170) entre os membros de um grupo pode oferecer uma forte identidade a uma equipe e forjar laços mais fortes entre eles. Uma identidade de grupo forte e positiva atua como uma força de atração, e promove a solidariedade numa coletividade. Kang e Kim (2010) definem a identificação com o grupo como uma força que conecta ou atrai o indivíduo ao grupo. Quando um indivíduo tem uma forte identificação com um grupo, o destino do grupo e seus processos e resultados coletivos tornam-se importantes para o seu autoconceito, estimulando, então, o comportamento de cooperação (Kane, 2010; Wachelke, 2013). A identificação com o grupo de trabalho deve, portanto, promover uma atitude favorável ao compartilhamento de conhecimento (Sordi et al., 2014). Assim, propõese:

Hipótese 8: a identificação com o grupo de trabalho influencia positivamente a atitude do indivíduo em relação ao compartilhamento de conhecimento.

Estudos recentes sugerem que a liderança de grupos de trabalho teria um papel relevante na promoção do compartilhamento de conhecimento (Barbosa et al., 2012; Correia, 2013; Donato et al., 2017; Lee, Gillespie, Mann, \& Wearing, 2010; Santos \& Bastos, 2019; Tonet \& Paz, 2006; Xue et al., 2011). Entre as teorias contemporâneas de liderança, a de maior destaque nas pesquisas internacionais é a teoria da liderança transformacional (Gardner,
Lowe, Moss, Mahoney, \& Cogliser, 2010; Judge \& Piccolo, 2004). Líderes transformacionais inspiram a admiração de seus seguidores e sua motivação para alcançar objetivos e interesses coletivos, estimulando-os intelectualmente e provendo suporte às suas necessidades (Bass \& Riggio, 2005; Bass, 1985; Marotto, Roos, \& Victor, 2007). A liderança transformacional está associada a comportamentos que transcendem interesses individuais, como a colaboração e o altruísmo (Cavazotte, Moreno, \& Bernardo, 2013; Choi, 2009; Marotto et al., 2007), bem como ao comportamento cidadão entre os membros de um grupo (Cho \& Dansereau, 2010), categoria com a qual a partilha de conhecimento estaria associada (LePine, Erez, \& Johnson, 2002). Portanto, propõe-se:

Hipótese 9: a liderança transformacional influencia positivamente a atitude do indivíduo em relação ao compartilhamento de conhecimento.

A atuação de um líder transformacional é também importante para a construção de um ambiente favorável a interações positivas, favorecendo as trocas sociais e a existência de normas de cooperação mais claras e amplamente compartilhadas (Chi \& Huang, 2014; De Cremer \& Van Knippenberg, 2002; H. Wang, Law, Hackett, Wang, \& Chen, 2005). Carmeli, Atwater e Levi (2011) sugerem que a liderança pode estimular o compartilhamento do conhecimento ao reforçar vínculos relacionais e organizacionais. Assim, ao criar um forte espírito de corpo em grupos de trabalho, líderes transformacionais devem fortalecer as crenças coletivas sobre a importância do compartilhamento de conhecimento pelo grupo e pelo líder. Propõe-se, então:

Hipótese 10: a liderança transformacional influencia positivamente as normas subjetivas associadas aos pares do indivíduo, relativas ao compartilhamento de conhecimento.

Hipótese 11: a liderança transformacional influencia positivamente as normas subjetivas associadas ao superior hierárquico do indivíduo, relativas ao compartilhamento de conhecimento.

Ainda, a liderança transformacional tem sido associada à confiança dos indivíduos em sua capacidade para realizar ações específicas, tanto em função da aquisição de competências relevantes, como pela viabilidade dos meios necessários para realizar tais tarefas por esses líderes (Mannheim \& Halamish, 2008). Assim, uma liderança transformacional também poderia promover mais oportunidades para a partilha de conhecimento e a eliminação de barreiras para o compartilhamento do conhecimento. Portanto: 
Hipótese 12: a liderança transformacional influencia positivamente as oportunidades de compartilhar conhecimento percebidas pelo indivíduo no trabalho.
A figura 1 representa graficamente as hipóteses do modelo proposto. Nela, foram incluídas três variáveis de controle: experiência, escolaridade e sexo

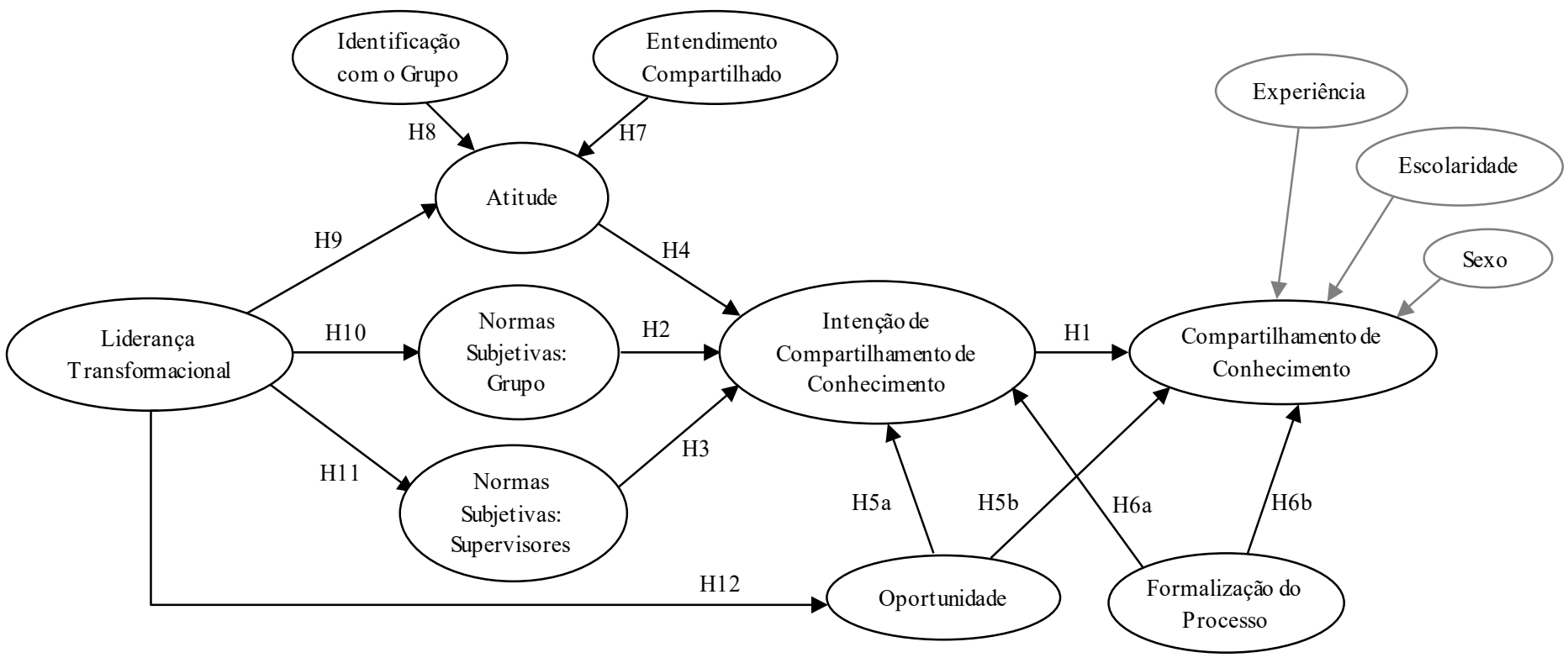

Figura 1. Modelo proposto.

\section{MÉTODO DE PESQUISA}

\section{Operacionalização dos construtos}

O Apêndice 1 lista os itens das dez escalas utilizadas na pesquisa. A seguir, detalhamos suas fontes e eventuais ajustes feitos no âmbito desta pesquisa.

As escalas utilizadas para operacionalizar os construtos Compartilhamento de Conhecimento (ação), Intenção de Compartilhar Conhecimento, e Atitude, foram originalmente criadas por Ajzen (1985) e Davenport e Prusak (1998), e adaptadas para o contexto do compartilhamento de conhecimento por I. Chen, Chen e Kinshuk (2009). Para avaliar as Normas Subjetivas relativas ao compartilhamento de conhecimento atribuídas a pares e superiores hierárquicos, foram utilizadas as duas dimensões da escala desenvolvida por Tracey, Tannenbaum e Kavanagh (1995) para avaliar crenças individuais sobre a ênfase em aprendizagem e conhecimento numa organização.

Tendo em vista o papel do contexto para a criação de conhecimentos (Von Krogh, Ichijo, \& Nonaka, 2000), o construto de controle comportamental percebido relativo a Oportunidade foi medido com a escala de Moreno e Cavazotte (2015), adaptada para o contexto de compartilhamento de conhecimento.
O instrumento indaga acerca da existência de circunstâncias favoráveis para obtenção e aplicação de conhecimentos no ambiente de trabalho. Para avaliar o controle comportamental associado à existência de um Processo Formalizado, foi desenvolvida uma métrica específica, tendo como base a escala elaborada por Durcikova e Gray (2009) para mensurar o constructo Transparência do Processo de Validação.

O construto Entendimento Compartilhado foi mensurado com a escala original de Nelson e Cooprider (1996) e Gerwin e Moffat (1997), adaptada por Ko, Kirsch e King (2005). Dela, apenas os itens pertinentes ao compartilhamento de conhecimento foram utilizados no instrumento deste estudo.

A Identificação com o Grupo foi mensurada com a escala adaptada por van Knippenberg, Haslam e Platow (2007) para o nível do grupo, tendo por base o trabalho de Ashforth e Mael (1989).

Para avaliar Liderança Transformacional, utilizou-se o questionário HSA-TFLde Quijano, Navarro, Yepes, Berger e Romeo (2008), que avalia a percepção do subordinado das qualidades transformacionais do seu líder/supervisor. O instrumento é convergente com o MLQ - Multifactorial Leadership Questionnaire, de Bass (1985) (Berger, Yepes, Gómez-Benito, Quijano, \& Brodbeck, 2011), porém mais sucinto. A versão 
adotada no estudo foi a de Carvalho (2012), traduzida para o português.

As variáveis de controle (sexo, escolaridade e experiência) foram mensuradas por meio de perguntas com alternativas de resposta que representavam categorias (ex., sexo feminino ou masculino) ou categorias ordenadas (ex.: primeiro grau, segundo grau, etc.).

\section{Coleta de dados}

Os dados foram coletados via questionário eletrônico junto a funcionários da área de atendimento ao cliente de uma grande empresa brasileira de telefonia móvel. Quando da realização da pesquisa, a empresa tinha mais de 70 milhões de linhas ativas e 10 unidades de call center em todo o Brasil, sendo quatro próprias e seis terceirizadas, totalizando quase 10 mil funcionários. O estudo envolveu apenas os que atuavam numa unidade da empresa que atendia clientes de alto valor (segmento pessoa física com planos pós-pago mais caros). Essa restrição foi adotada para garantir que houvesse uma demanda razoável para a troca de conhecimentos entre pares, dada a maior complexidade das atividades desempenhadas, se comparadas às dos funcionários que atendiam outros segmentos. Os participantes do estudo utilizavam rotineiramente inúmeros sistemas computacionais simultaneamente num único atendimento (ex., sistema de procedimentos, sistemas de faturamento e ativação pós-pago e prépago, sistema de controle de adimplência, sistema de fidelização). A falta de um sistema único e a diversidade de demandas dos clientes tornava o seu trabalho especializado e complexo.

Após concordar em participar do estudo, a empresa forneceu os e-mails dos 470 funcionários do call center, os quais eram segmentados em células de atendimento. Os pesquisadores lhes enviaram um convite destacando os objetivos do estudo, a confidencialidade dos dados coletados, e os procedimentos envolvidos. No total, foram respondidos 185 questionários, dos quais 131 estavam completamente preenchidos (taxa de resposta de 28\%).

A análise demográfica da amostra indicou que $76 \%$ dos participantes eram mulheres, com idades entre 19 e 58 anos, média de 31 anos e desvio padrão de 8 anos. Quanto à escolaridade, $91 \%$ dos participantes possuíam o segundo grau completo, e 9\%, o ensino superior. Essas proporções não apresentaram diferenças estatisticamente significantes em relação às que caracterizavam a força de trabalho do call center da empresa.

\section{RESULTADOS}

O teste das hipóteses propostas neste estudo foi feito por meio de modelagem de equações estruturais com o método de Mínimos Quadrados Parciais (Partial Least Squares - PLS). As análises estatísticas foram conduzidas no software SmartPLS 2.0 M3. O método PLS é robusto a violações da normalidade multivariada, permite o tratamento adequado de construtos formativos e reflexivos, e requer tamanhos de amostra menores do que as técnicas de modelagem de equações estruturais baseadas em covariância (Chin, 2010; Hair, Hult, Ringle, \& Sarstedt, 2014). Além de a amostra do estudo ter um tamanho reduzido frente ao número de parâmetros a serem estimados, a análise dos dados obtidos revelou desvios em relação à premissa de normalidade multivariada.

Hair, Hult, Ringle e Sarstedt (2014) ressaltam que não existe um único critério para avaliar a qualidade das estimativas de um modelo (goodness-of-fit) em PLS. Em vez disso, são usados critérios de avaliação não-paramétricos baseados em bootstrapping e blindfolding. Empregou-se no estudo a técnica de bootstrapping com 1.000 amostras de 131 casos para avaliar a significância dos efeitos estimados (Chin, 2010).

A avaliação da qualidade do modelo de mensuração foi feita por meio de uma análise fatorial confirmatória (CFA). Conforme sugerido por Hair et al. (2014), itens com cargas abaixo de 0,70 foram eliminados, bem como os que estavam fortemente associados a variáveis latentes que não a de sua própria escala, gerando valores abaixo do recomendado de Variância Média Extraída (AVE) e Confiabilidade Composta (CR). Após os ajustes, uma nova CFA foi executada. Seus resultados mostraram que todos os itens carregavam apropriadamente em suas respectivas variáveis, com cargas estatisticamente significantes $(\mathrm{p}<0,001)$ e superiores a 0,70 .

A Tabela 1 sintetiza os resultados globais do modelo de mensuração. Os valores de Variância Média Extraída (AVE), Confiabilidade Composta (CR), e alfa de Cronbach $(\alpha C)$, e o fato de que o valor da raiz quadrada de AVE para cada variável é maior do que as correlações da respectiva variável latente com as demais comprovam a validade convergente e discriminante das variáveis mensuradas (Chin, 2010; Hair et al., 2014; Hair, Ringle, \& Sarstedt, 2013). 
Tabela 1. Resultados do modelo de mensuração.

\begin{tabular}{|c|c|c|c|c|c|c|c|c|c|c|c|c|c|c|c|}
\hline \multirow[b]{2}{*}{ Var. Latentes } & \multirow[b]{2}{*}{ Item } & \multirow[b]{2}{*}{ Méd. } & \multirow[b]{2}{*}{ AVE } & \multirow[b]{2}{*}{$\mathrm{CR}$} & \multirow[b]{2}{*}{$\alpha_{C}$} & \multicolumn{10}{|c|}{ Correlações } \\
\hline & & & & & & 1 & 2 & 3 & 4 & 5 & 6 & 7 & 8 & 9 & 10 \\
\hline 1. Atitude & 4 & 4,50 & 0,78 & 0,93 & 0,90 & 0,88 & - & - & - & - & - & - & - & - & - \\
\hline $\begin{array}{l}\text { 2. Entendimento } \\
\text { compartilhado }\end{array}$ & 5 & 3,97 & 0,58 & 0,87 & 0,82 & 0,38 & 0,76 & - & - & - & - & - & - & - & - \\
\hline $\begin{array}{l}\text { 3. Grupo (Normas } \\
\text { Subjetivas) }\end{array}$ & 4 & 3,98 & 0,58 & 0,85 & 0,76 & 0,45 & 0,66 & 0,76 & - & - & - & - & - & - & - \\
\hline $\begin{array}{l}\text { 4. Identificação com o } \\
\text { grupo }\end{array}$ & 3 & 4,21 & 0,72 & 0,88 & 0,80 & 0,46 & 0,37 & 0,46 & 0,85 & - & - & - & - & - & - \\
\hline $\begin{array}{l}\text { 5. Int. comp. } \\
\text { Conhecimento }\end{array}$ & 4 & 4,47 & 0,66 & 0,89 & 0,83 & 0,65 & 0,35 & 0,45 & 0,51 & 0,81 & - & - & - & - & - \\
\hline $\begin{array}{l}\text { 6. Liderança } \\
\text { transformacional }\end{array}$ & 14 & 3,98 & 0,73 & 0,97 & 0,97 & 0,29 & 0,19 & 0,26 & 0,21 & 0,26 & 0,86 & - & - & - & - \\
\hline 7. Oportunidade & 3 & 3,15 & 0,83 & 0,93 & 0,90 & 0,18 & 0,19 & 0,27 & 0,20 & 0,15 & 0,38 & 0,91 & - & - & - \\
\hline 8. Processos formalizados & 5 & 3,42 & 0,62 & 0,89 & 0,85 & 0,20 & 0,25 & 0,32 & 0,18 & 0,22 & 0,54 & 0,58 & 0,79 & - & - \\
\hline $\begin{array}{l}\text { 9. Supervisor (Normas } \\
\text { Subj.) }\end{array}$ & 6 & 3,49 & 0,61 & 0,90 & 0,87 & 0,21 & 0,21 & 0,43 & 0,30 & 0,21 & 0,64 & 0,44 & 0,55 & 0,78 & - \\
\hline $\begin{array}{l}\text { 10. Compart. } \\
\text { Conhecimento }\end{array}$ & 3 & 4,30 & 0,58 & 0,80 & 0,64 & 0,61 & 0,30 & 0,40 & 0,46 & 0,74 & 0,26 & 0,19 & 0,21 & 0,24 & 0,76 \\
\hline
\end{tabular}

Nota. Os valores em negrito na diagonal da tabela de correlações correspondem à raiz quadrada da Variância Média Extraída (AVE).

A figura 2 apresenta os resultados obtidos para o modelo estrutural. As proporções das variâncias dos construtos de interesse explicadas pelo modelo foram substanciais, à exceção das relativas às normas subjetivas associadas ao grupo de trabalho $\left(\mathrm{R}^{2}=\right.$ $0,07)$. Deve-se destacar que o modelo foi capaz de explicar $47 \%$ da variância observada para a intenção de compartilhar conhecimentos e $58 \%$ da variância observada para o compartilhamento de conhecimento. Esses resultados indicam que o modelo proposto apresenta boa capacidade de explicação das variáveis de interesse.

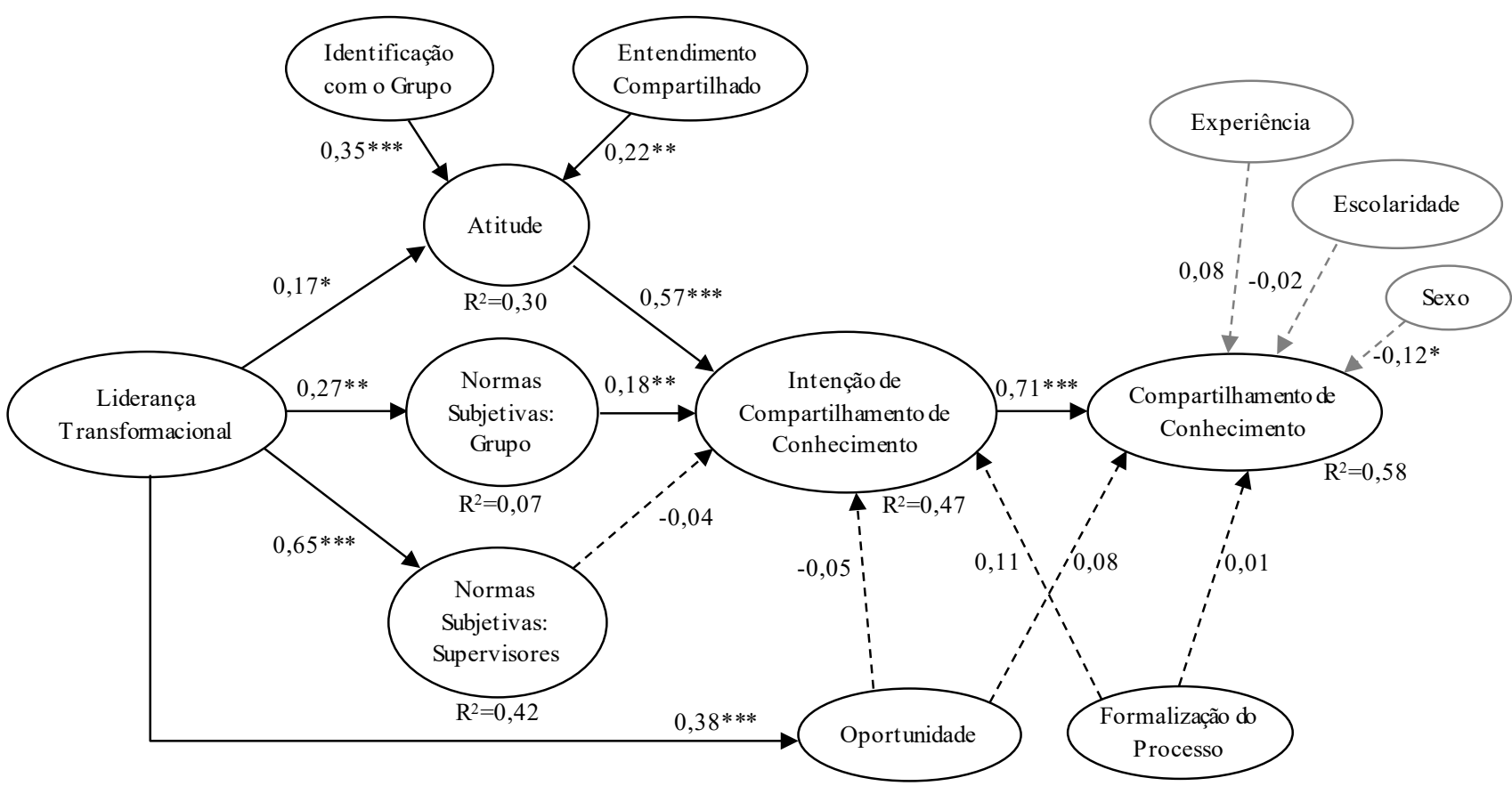

Figura 2. Resultados do modelo estrutural.

$N=131 ; * \mathrm{p}<0,05 ;{ }^{* *} \mathrm{p}<0,01 ; * * * \mathrm{p}<0,001$. 
Das quatorze hipóteses do estudo, nove obtiveram suporte empírico. A Liderança Transformacional do supervisor direto do indivíduo teve forte influência nos construtos exógenos da Teoria do Comportamento Planejado, a saber Atitude (H9), Normas Subjetivas do grupo (H10) e do supervisor (H11), e Controle Comportamental Percebido (no caso, representado pelo construto Oportunidade) (H12). Da mesma forma, o Entendimento Compartilhado e a Identificação com o Grupo mostraram-se determinantes importantes da Atitude do indivíduo em relação ao compartilhamento de conhecimento (H7 e H8, respectivamente). Por sua vez, a Atitude (H4) sobressaiu-se dentre os antecedentes da Intenção de Compartilhar Conhecimentos, apresentando um efeito direto três vezes mais forte que as Normas Subjetivas do grupo (H2). Por fim, como previsto pela TCP, o Comportamento de Compartilhamento foi fortemente influenciado pela Intenção do indivíduo de realizar esse comportamento (H1).

Ao contrário do que se esperava, nenhuma das hipóteses associadas ao Controle Comportamental foi comprovada (H5a, H5b, H6a, H6b). Os resultados também sugerem que a Intenção de Compartilhar Conhecimento não parece ser afetada pelas Normas Subjetivas associadas ao supervisor direto do indivíduo (H3), e sim apenas pelas relacionadas a seu grupo (H2).

Apenas uma das variáveis de controle (Sexo) apresentou um coeficiente estimado estatisticamente significante. O resultado sugere que, na população pesquisada, mulheres tendem a transferir menos conhecimento para seus pares do que homens.

Os efeitos totais médios calculados no processo de bootstrapping, mostrados na Tabela 2 , indicam que as variáveis associadas à percepção do indivíduo de fatores relacionados a seu grupo de trabalho (Entendimento Compartilhado, Normas Subjetivas do Grupo, e Identificação com o Grupo) são os principais determinantes de sua Intenção de Compartilhar seus Conhecimentos com seus pares. O Comportamento de Compartilhamento de Conhecimento em si sofre maior influência da Atitude do indivíduo, e, por meio desta, dos fatores supracitados.

Tabela 2. Efeitos totais médios obtidos por bootstrapping.

\begin{tabular}{lccc}
\hline & $\begin{array}{c}\text { Intenção de compartilhamento } \\
\text { Variáveis latentes }\end{array}$ & Erro padrão & \multicolumn{2}{c}{$\begin{array}{c}\text { Compartilhamento } \\
\text { Efro padrão }\end{array}$} \\
\hline Atitude & - & - & $0,40^{* * *}$ \\
\hline $\begin{array}{l}\text { Entendimento } \\
\text { compartilhado }\end{array}$ & $0,13^{*}$ & 0,05 & $0,09^{*}$ \\
\hline Grupo (Normas Subj.) & $0,19^{* *}$ & 0,07 & 0,04 \\
\hline Identificação com o Grupo & $0,20^{* *}$ & 0,07 & $0,13^{* *}$ \\
\hline Liderança Transformacional & 0,10 & 0,09 & $0,14^{*}$ \\
\hline Oportunidade & $-0,05$ & 0,08 & 0,11 \\
\hline Processos Formalizados & 0,12 & 0,09 & 0,06 \\
\hline Supervisor (Normas Subj.) & $-0,04$ & 0,08 & 0,09 \\
\hline
\end{tabular}

Nota. Os valores de erro padrão foram calculados com a técnica de bootstrapping denominada Bias-Corrected and Accelerated (BCa), que busca corrigir problemas gerados por viés e assimetria na distribuição das estimativas (Chernick, M. R., \& LaBudde, R. A. (2011). An introduction to bootstrap methods with applications to R. Hoboken, N.J: Wiley).

Uma vez que, no questionário da pesquisa, as avaliações de todas as variáveis do modelo são feitas por um único respondente, é importante que se considere a possibilidade da introdução de viés de método comum (common method bias). Para avaliar a presença desse viés, foi empregado o teste de um fator de Harmon (Malhotra, Kim, \& Patil, 2006; Patnayakuni, Rai, \& Tiwana, 2007; Podsakoff \& Organ, 1986). Todos os indicadores das variáveis latentes do modelo proposto foram incluídos numa análise fatorial exploratória (AFE). Nove fatores com autovalor acima de 1,0 foram identificados, explicando $73,1 \%$ da variação na amostra. Como o primeiro fator gerado respondeu por menos de $50 \%$ dessa variação, pode-se concluir que é improvável que os resultados das análises tenham sido afetados pelo viés de método comum. 


\section{CONCLUSÃO}

O modelo proposto e avaliado neste trabalho foi elaborado com base na Teoria do Comportamento Planejado (TCP) (Ajzen, 1985; 1991; 2012) e estendido ao contexto do compartilhamento de conhecimento no ambiente de trabalho. No modelo, os elementos centrais da formação de intenções comportamentais da TCP (atitude, normas subjetivas e controle comportamental) passaram a ser fatores endógenos explicados por antecedentes psicossociais exógenos (identificação com o grupo, entendimento compartilhado, liderança transformacional). Além disso, dois fatores organizacionais (oportunidade e processos formalizados) foram incluídos como antecedentes da intenção e comportamento de compartilhamento de conhecimento. Dada a escassez de pesquisas empíricas e de natureza quantitativa sobre o compartilhamento de conhecimento no nível do indivíduo (Levine \& Prietula, 2012), o presente trabalho é uma contribuição importante para o estudo do tema, especialmente no contexto brasileiro, integrando fatores psicossociais e organizacionais à TPB e analisando sua importância relativa para promover o compartilhamento de conhecimento nas organizações.

Os resultados confirmam a aderência de grande parte do modelo proposto aos dados coletados numa grande empresa brasileira de telefonia. Aproximadamente $60 \%$ da variação do comportamento de compartilhamento de conhecimento foram explicados pelos construtos do modelo. Conforme sugerido por Ajzen (2012), a intenção de compartilhar conhecimento foi o fator com maior influência na realização desse comportamento, sendo ela própria fortemente influenciada pela atitude do indivíduo sobre o compartilhamento.

A integração de fatores psicossociais à TPB é uma contribuição inédita do estudo, esclarecendo como elementos associados às interações humanas e à atuação dos supervisores podem influenciar a motivação dos indivíduos para compartilhar conhecimentos com seus pares. Em linha com resultados recentes (Ghobadi, 2015; Rosenkranz et al., 2014), a proximidade cognitiva entre os membros do grupo, refletida na percepção do indivíduo de entendimento compartilhado com seu grupo de trabalho, foi um elemento importante na formação de atitudes favoráveis ao compartilhamento de conhecimento. Adicionalmente, indivíduos com maior identificação com o seu grupo tenderam a ter atitudes mais positivas em relação ao compartilhamento de seus conhecimentos (Kang \& Kim, 2010). Essa atitude tende a ser mais positiva quando o supervisor direto do indivíduo adota um estilo de liderança mais transformacional.

Observou-se também que liderança transformacional está associada às normas sociais subjetivas atribuídas tanto ao grupo de trabalho do indivíduo como a seu supervisor direto, bem como às oportunidades de compartilhamento percebidas pelos participantes. Verificou-se que os líderes são um importante fator no contexto estudado. Sua influência se estende desde a formação de uma cultura de troca de conhecimento no grupo e difusão de princípios que estimulam essa troca, até a viabilização de oportunidades por meio de uma gestão ativa da difusão de conhecimento nas equipes (Chi \& Huang, 2014; Choi, 2009).

Por outro lado, na população contemplada na pesquisa, as normas sociais atribuídas aos supervisores parecem não estar associadas à atitude do indivíduo sobre o compartilhamento de conhecimento com seu grupo de trabalho. É possível que esse resultado seja um reflexo da rotina dos participantes, que tipicamente atuam em maior proximidade física uns dos outros do que de seus superiores hierárquicos. Essa situação deve estimular interações sociais mais frequentes e intensas entre os membros de um grupo, do que entre eles e seu supervisor direto. Como consequência, as normas subjetivas do grupo teriam maior relevância para a formação de atitudes positivas sobre o compartilhamento de conhecimento entre pares do que as relacionadas aos supervisores. Estudos empíricos sugerem que atitudes em relação a entidades sociais mais próximas dos indivíduos (ex., equipe vs. organização; pares vs. chefia) exercem uma influência maior sobre atitudes e comportamentos que beneficiam o grupo de trabalho (Becker, 2009), em linha com o resultado obtido nesta pesquisa. Estudos futuros devem analisar a importância relativa de normas sociais associadas a diferentes entidades, sua influência sobre os membros das organizações, e as condições que determinam sua precedência.

Também não se obteve suporte para as hipóteses que relacionam o controle comportamental à intenção e comportamento de compartilhamento de conhecimento. Uma possível explicação seria a preferência dos participantes pelo uso de mecanismos informais para compartilhar conhecimentos. É possível que os meios disponíveis na organização não fossem atrativos a ponto de os participantes optarem por utilizá-los quando tinham a 
oportunidade. Outra possibilidade é que esses meios não estivessem devidamente alinhados às oportunidades e procedimentos formais de compartilhamento de conhecimento. No caso de ferramentas computacionais, dificuldades desse tipo tenderiam a reduzir a percepção dos usuários da sua facilidade de uso e utilidade, diminuindo sua intenção de uso no compartilhamento de conhecimentos (ex.: Venkatesh\&Bala, 2008). Defato, informações qualitativas obtidas informalmente em conversas e observações realizadas na empresa pelos pesquisadores sugerem que vários participantes se utilizavam de redes sociais extraorganizacionais para compartilhar conhecimentos com seus pares. Em linha com esses resultados, estudos recentes mostram que a difusão de novas tecnologias da informação associada à crescente adoção de dispositivos móveis favorece o uso de mecanismos informais para a troca de informações nas empresas, em detrimento das estruturas formais por elas disponibilizadas (Davison, Ou, \& Martinsons, 2013; Vaessen, Van Den Beemt, \& De Laat, 2014). Além disso, no caso de conhecimentos tácitos, o compartilhamento tende a ocorrer prioritariamente por meio do contato direto entre indivíduos e mecanismos de socialização frequentemente informais (Davison et al., 2013; Park, Vertinsky, \& Becerra, 2015; Takeuchi \& Nonaka, 2008). Sugere-se, portanto, que pesquisas sejam desenvolvidas para explicitar e avaliar a relação entre os diferentes processos e meios formais e informais de compartilhamento de conhecimento adotados por indivíduos nas organizações. Tais estudos seriam de grande importância para empresas que investem na Gestão do Conhecimento, especialmente na medida em que a proteção de tais ativos vem se tornando crítica para a obtenção de vantagem competitiva (Jean, Sinkovics, \& Hiebaum, 2014; Lawson, Samson, \& Roden, 2012).

Este estudo tem por limitação o fato de empregar dados coletados numa única organização. Embora gere barreiras para uma generalização mais imediata dos resultados, essa restrição permitiu que fossem controlados fatores relacionados ao ambiente de trabalho dos participantes, como: direcionamento e objetivos estratégicos; cultura organizacional; políticas, procedimentos e normas; acesso a treinamento e materiais de consulta; e infraestrutura disponível. Mesmo que adequadamente mensurados, tais fatores, se contemplados no modelo proposto, iriam requerer que o tamanho da amostra analisada fosse substancialmente maior, o que poderia inviabilizar a realização da pesquisa. Ressalta-se que a especificidade da população do estudo não impede a generalização dos resultados para contextos similares, ou seja, grupos de trabalho cujas atividades envolvam um nível razoável de complexidade operacional, exigências relativamente baixas de nível educacional e área de formação específica, e pouca interação formal para a geração dos resultados individuais esperados. Mesmo assim, recomenda-se a realização de pesquisas em diferentes contextos organizacionais, principalmente em empresas brasileiras, dada a escassez de estudos quantitativos sobre o compartilhamento de conhecimento entre pares na literatura nacional.

Os resultados obtidos ressaltam a importância dos grupos sociais na construção de ambientes de trabalho que favoreçam a aprendizagem contínua e o compartilhamento de conhecimento (Tracey et al., 1995). Sugerem, portanto, que empresas que desejem estimular tal comportamento entre seus empregados devem investir em medidas que fortaleçam os laços entre os membros das equipes de trabalho, ao mesmo tempo que promovam a sedimentação de valores compartilhados compatíveis com a geração, troca, e aplicação de conhecimentos. O desenvolvimento de líderes com estilo transformacional seria instrumental para esse fim. Organizações que forem bemsucedidas em tais esforços estariam aptas a colher os benefícios associados ao tratamento do conhecimento como ativo capaz de gerar vantagem competitiva sustentável (Grant, 1996). 


\section{REFERENCIAS}

Ajzen, I. (1985). From intentions to actions: A theory of planned behavior. In J. Kuhl \& J. Beckmann (Eds.), Action Control (pp. 11-39). Heidelberg: Springer

Ajzen, I. (1991). The theory of planned behavior. Organizational Behavior and Human Decision Processes, 50(2), 179211. https://doi.org/10.1016/0749-5978(91)90020-T

Ajzen, I. (2012). The theory of planned behavior. In P. A. M. Lange, A. W. Kruglanski, \& E. T. Higgins (Eds.), Handbook of theories of social psychology (Vol. 1, pp. 438-459). London: Sage Publications.

Alavi, M., \& Leidner, D. E. (2001). Review: Knowledge management and knowledge management systems: Conceptual foundations and research issues. MIS Quarterly, 25(1), 107-136. http://dx.doi.org/10.2307/3250961

Argote, L., \& Ingram, P. (2000). Knowledge transfer: A basis for competitive advantage in firms. Organizational Behavior and Human Decision Processes, 82(1), 150169. https://doi.org/10.1006/obhd.2000.2893

Ashforth, B. E., \& Mael, F. (1989). Social identity theory and the organization. The Academy of Management Review, 14(1), 20-39. https://doi.org/10.2307/258189

Barbosa, J. G. P., Monteiro, L. S. I., \& Freitas, J. A. de S. B. e. (2012). Compartilhamento de conhecimento: Um estudo de caso em uma instituição financeira. Perspectivas em Gestão \& Conhecimento, 2(1), 137-154. Retrieved from http://hdl.handle.net/20.500.11959/brapci/52468

Barney, J. (1991). Firm resources and sustained competitive advantage. Journal of Management, 17(1), 99-120. https://doi.org/10.1177/014920639101700108

Bass, B. M., \& Riggio, R. E. (2005). Transformational Leadership. Mahwah, NJ: Lawrence Erlbaum Associates

Bass, B. M. (1985). Leadership and performance beyond expectations. New York: The Free Press

Becker, T. E. (2009). Interpersonal commitments. In H. J. Klein, T. E. Becker, \& J. P. Meyer (Eds.), Commitment in organizations: Accumulated wisdom and new directions. New York: Routledge.

Berger, R., Yepes, M., Gómez-Benito, J., Quijano, S., \& Brodbeck, F. C. (2011). Validity of the human system audit transformational leadership short scale (HSA-TFL) in four european countries. Universitas Psychologica, 10(3), 657-668. Retrieved from http://www.scielo. org.co/scielo.php?script=sci_arttext\&pid=S1657$92672011000300002 \& \operatorname{lng}=$ en\&tlng=en.

Bock, G.-W., Zmud, R. W., Kim, Y.-G., \& Lee, J.-N. (2005). Behavioral intention formation in knowledge sharing: Examining the roles of extrinsic motivators, social-psychological forces, and organizational climate. MIS Quarterly, 29(1), 87-111. https://doi.org/10.2307/25148669

Carlile, P. R., \& Rebentisch, E. S. (2003). Into the black box: The knowledge transformation cycle. Management Science, 49(9), 1180-1195. https://doi.org/10.1287/ mnsc.49.9.1180.16564

Carmeli, A., Atwater, L., \& Levi, A. (2011). How leadership enhances employees' knowledge sharing: The intervening roles of relational and organizational identification. Journal of Technology Transfer, 36(3), 257-274. https://doi.org/10.1007/s10961-010-9154-y
Carvalho, R. A. S. (2012). Estilo de liderança percebido e interacção trabalho-família: Que relação? (Dissertação de Mestrado). Universidade de Coimbra, Coimbra, Portugal.

Cavazotte, F., Moreno, V., \& Bernardo, J. (2013). Transformational leaders and work performance: The mediating roles of identification and self-efficacy. BAR - Brazilian Administration Review, 10(4), 490-512. http://dx.doi. org/10.1590/S1807-76922013000400007

Chen, I. Y. L., Chen, N.-S., \& Kinshuk (2009). Examining the factors influencing participants' knowledge sharing behavior in virtual learning communities. Journal of Educational Technology \& Society, 12(1), 134-148. Retrieved from https://eric.ed.gov/?id=EJ833422

Chen, S.-S., Chuang, Y.-W., \& Chen, P.-Y. (2012). Behavioral intention formation in knowledge sharing: Examining the roles of KMS quality, KMS self-efficacy, and organizational climate. Knowledge-Based Systems, 31, 106-118. https://doi.org/10.1016/j. knosys.2012.02.001

Chernick, M. R., \& LaBudde, R. A. (2011). An introduction to bootstrap methods with applications to R. Hoboken, N.J: Wiley.

Chi, N.-W., \& Huang, J.-C. (2014). Mechanisms linking transformational leadership and team performance: The mediating roles of team goal orientation and group affective tone. Group \& Organization Management, 39(3), 300-325. https://doi. org/10.1177/1059601114522321

Chin, W. W. (2010). How to write up and report PLS analyses. In V. E. Vinzi, W. W. Chin, J. Henseler, \& H. Wang (Eds.), Handbook of partial least squares: Concepts, methods and applications (pp. 655-690). Berlin: Springer-Verlag.

Cho, J., \& Dansereau, F. (2010). Are transformational leaders fair? A multi-level study of transformational leadership, justice perceptions, and organizational citizenship behaviors. The Leadership Quarterly, 21(3), 409-421. https://psycnet.apa.org/doi/10.1016/j. leaqua.2010.03.006

Choi, J. N. (2009). Collective dynamics of citizenship behaviour: What group characteristics promote group-level helping? Journal of Management Studies, 46(8), 13961420. https://psycnet.apa.org/doi/10.1111/j.14676486.2009.00851.x

Correia, R. R. (2013). Associações entre princípios sociotécnicos e compartilhamento de conhecimento: Estudo de caso em projetos de sistemas de informação. Perspectivas Em Gestão \& Conhecimento, 3(1), 175-191. Retrieved from http://hdl.handle.net/20.500.11959/brapci/49633

Davenport, T., \& Prusak, L. (1998). Conhecimento empresarial: Como as organizações gerenciam seu capital intelectual. Rio de Janeiro: Editora Campus.

Davison, R. M., Ou, C. X. J., \& Martinsons, M. G. (2013). Information technology to support informal knowledge sharing. Information Systems Journal, 23(1), 89-109. https://doi.org/10.1111/j.1365-2575.2012.00400.x 
De Cremer, D., \& Van Knippenberg, D. (2002). How do leaders promote cooperation? The effects of charisma and procedural fairness. Journal of Applied Psychology, 87(5), 858-866. https://psycnet.apa.org/ doi/10.1037/0021-9010.87.5.858

DeSanctis, G., \& Poole, M. S. (1997). Transitions in teamwork in new organizational forms. In B. Markovsky, M. J. Lovaglia, \& E. J. Lawler (Eds.), Advances in group processes (Vol. 14, pp. 157-176). London: JAI Press.

Dewhurst, M., Ellsworth, D., \& Hancock, B. (2013). Redefina o trabalho do conhecimento: Como liberar profissionais altamente especializados para fazer o que melhor fazem. Harvard Business Review - Brasil, 92, 3441. Retrieved from https://www.yumpu.com/pt/ document/read/12797039/redefina-o-trabalho-doconhecimento-plugar

Donato, A., Hedler, H. C., \& Coelho Junior, F. A. (2017). Informal learning exercise for TIC professionals: A study at the superior military court. RAM. Revista de Administração Mackenzie, 18(1), 66-95. http:// dx.doi.org/10.1590/1678-69712017/administracao. v18n1p66-95

Durcikova, A., \& Gray, P. (2009). How knowledge validation processes affect knowledge contribution. Journal of Management Information Systems, 25(4), 81-107. Retrieved from https://www.jstor.org/ stable/40398954

Erden, Z., Von Krogh, G., \& Kim, S. (2012). Knowledge sharing in an online community of volunteers: The role of community munificence. European Management Review, 9(4), 213-227. https://doi.org/10.1111/ j.1740-4762.2012.01039.x

Gardner, W. L., Lowe, K. B., Moss, T. W., Mahoney, K. T., \& Cogliser, C. C. (2010). Scholarly leadership of the study of leadership: A review of the leadership quarterly's second decade, 2000-2009. The Leadership Quarterly, 21(6), 922-958. https://psycnet.apa.org/ doi/10.1016/j.leaqua.2010.10.003

Gerwin, D., \& Moffat, L. (1997). Withdrawal of team autonomy during concurrent engineering. Management Science, 43(9), 1275-1287. https://doi.org/10.1287/ mnsc.43.9.1275

Ghobadi, S. (2015). What drives knowledge sharing in software development teams: A literature review and classification framework. Information \& Management, 52(1), 82-97. https://doi.org/10.1016/j. im.2014.10.008

Grant, R. M. (1996). Toward a knowledge based theory of the firm. Strategic Management Journal, 17(S2), 109-122. https://doi.org/10.1002/smj.4250171110

Hair, J. F., Jr., Hult, G. T. M., Ringle, C., \& Sarstedt, M. (2014). A primer on partial least squares structural equation modeling (PLS-SEM). Thousand Oaks, CA: Sage Publications.

Hair, J. F., Ringle, C., \& Sarstedt, M. (2013). Partial least squares structural equation modeling: rigorous applications, better results and higher acceptance. Long Range Planning, 46(1-2), 1-12. https://doi.org/10.1016/j. lrp.2013.08.016

Hong, J. F. L., \& Vai, S. (2008). Knowledge-sharing in crossfunctional virtual teams. Journal of General Management, 34(2), 21-37. https://doi.org/10.1177\% 2F030630700803400202
Jean, R.-J. B.," Sinkovics, R. R., \& Hiebaum, T. P. (2014). The effects of supplier involvement and knowledge protection on product innovation in customer-supplier relationships: A study of global automotive suppliers in china. Journal of Product Innovation Management, 31(1), 98-113. https://doi.org/10.1111/jpim.12082

Judge, T. A., \& Piccolo, R. F. (2004). Transformational and transactional leadership: A meta-analytic test of their relative validity. Journal of Applied Psychology, 89(5), 755-768. https://psycnet.apa.org/doi/10.1037/00219010.89.5.755

Kane, A. A. (2010). Unlocking knowledge transfer potential: Knowledge demonstrability and superordinate social identity. Organization Science, 21(3), 643-660. https://psycnet.apa.org/doi/10.1287/orsc.1090.0469

Kang, M., \& Kim, Y.-G. (2010). A multilevel view on interpersonal knowledge transfer. Journal of the American Society for Information Science and Technology, 61(3), 483494. https://doi.org/10.1002/asi.21267

Ko, D.-G., Kirsch, L. J., \& King, W. R. (2005). Antecedents of knowledge transfer from consultants to clients in enterprise system implementations. MIS Quarterly, 29(1), 59-85. https://doi.org/10.2307/25148668

Kogut, B., \& Zander, U. (1996). What firms do? Coordination, identity, and learning. Organization Science, 7(5), 502-518. http://dx.doi.org/10.1287/orsc.7.5.502

Lawson, B., Samson, D., \& Roden, S. (2012). Appropriating the value from innovation: Inimitability and the effectiveness of isolating mechanisms. $R \& D$ Management, 42(5), 420-434. https://dx.doi. org/10.1111/j.1467-9310.2012.00692.x

Le, P. B., \& Lei, H. (2019). Determinants of innovation capability: The roles of transformational leadership, knowledge sharing and perceived organizational support. Journal of Knowledge Management, 23(3), 527-547. https:// doi.org/10.1108/JKM-09-2018-0568

Lee, P., Gillespie, N., Mann, L., \& Wearing, A. (2010). Leadership and trust: Their effect on knowledge sharing and team performance. Management Learning, 41(4), 473-491. https://doi.org/10.1177\%2F1350507610362036

LePine, J. A., Erez, A., \& Johnson, D. E. (2002). The nature and dimensionality of organizational citizenship behavior: A critical review and meta-analysis. Journal of Applied Psychology, 87(1), 52-65. https://psycnet.apa.org/ doi/10.1037/0021-9010.87.1.52

Levine, S. S., \& Prietula, M. J. (2012). How knowledge transfer impacts performance: A multilevel model of benefits and liabilities. Organization Science, 23(6), 1748-1766. http://dx.doi.org/10.1287/orsc.1110.0697

Liu, H., \& Li, G. (2018). Linking transformational leadership and knowledge sharing: The mediating roles of perceived team goal commitment and perceived team identification. Frontiers in Psychology, 9, 1331. http:// dx.doi.org/10.3389/fpsyg.2018.01331

Liyanage, C., Elhang, T., Ballal, T., \& Li, Q. (2009). Knowledge communication and translation: A knowledge transfer model. Journal of Knowledge Management, 13(3), 118131. http://dx.doi.org/10.1108/13673270910962914 
Malhotra, N. K., Kim, S. S., \& Patil, A. (2006). Common method variance in IS research: A comparison of alternative approaches and a reanalysis of past research. Management Science, 52(12), 1865-1883. https://doi. org/10.1287/mnsc.1060.0597

Mannheim, B., \& Halamish, H. (2008). Transformational leadership as related to team outcomes and contextual moderation. Leadership \& Organization Development Journal, 29(7), 617-630. https://doi. org/10.1108/01437730810906353

Marjanovic, O., \& Freeze, R. (2012). Knowledge-intensive business process: Deriving a sustainable competitive advantage through business process management and knowledge management integration. Knowledge \& Process Management, 19(4), 180-188. https://doi. org $/ 10.1002 / \mathrm{kpm} .1397$

Marotto, M., Roos, J., \& Victor, B. (2007). Collective virtuosity in organizations: A study of peak performance in an orchestra. Journal of Management Studies, 44(3), 388-413. https://doi.org/10.1111/j.14676486.2007.00682.x

Moreno Jr., V., \& Cavazotte, F. (2015). Using information systems to leverage knowledge management processes: The role of work context, job characteristics and tasktechnology fit. Procedia Computer Science, 55, 360369. https://doi.org/10.1016/j.procs.2015.07.066

Moreno, V. de A., \& Santos, L. H. A. dos. (2012). Gestão do conhecimento e redesenho de processos de negócio: Proposta de uma metodologia integrada. Perspectivas em Ciência da Informação, 17(1), 203-230. http:// dx.doi.org/10.1590/S1413-99362012000100012

Murray, S. R., \& Peyrefitte, J. (2007). Knowledge type and communication media choice in the knowledge transfer process. Journal of Managerial Issues, 19(1), 111-133. Retrieved from https://www.jstor.org/ stable/40601196

Nelson, K. M., \& Cooprider, J. G. (1996). The contribution of shared knowledge to IS group performance. MIS Quarterly, 20(4), 409-432. http://dx.doi. org/10.2307/249562

Park, C., Vertinsky, I., \& Becerra, M. (2015). Transfers of tacit vs. explicit knowledge and performance in international joint ventures: The role of age. International Business Review, 24(1), 89-101. https://doi.org/10.1016/j. ibusrev.2014.06.004

Patnayakuni, R., Rai, A., \& Tiwana, A. (2007). Systems development process improvement: A knowledge integration perspective. IEEE Transactions on Engineering Management, 54(2), 286-300. https://doi. org/10.1109/TEM.2007.893997

Podsakoff, P. M., \& Organ, D. W. (1986). Self-reports in organizational research: Problems and prospects. Journal of Management, 12(4), 531-544. https://doi.or $\mathrm{g} / 10.1177 \% 2 \mathrm{~F} 014920638601200408$

Probst, G., Raub, S., \& Romhart, K. (2002). Gestão do conhecimento: Os elementos construtivos do sucesso. São Paulo: Bookman.

Quijano, S., Navarro, J., Yepes, M., Berger, R., \& Romeo, M. (2008). Human system audit (HSA) for the analysis of human behaviour in organizations. Papeles Del Psicólogo, 29(1), 92-106. Retrieved from http://www. papelesdelpsicologo.es/English/1542.pdf
Rosenkranz, C., Vranešić, H., \& Holten, R. (2014). Boundary interactions and motors of change in requirements elicitation: A dynamic perspective on knowledge sharing. Journal of the Association for Information Systems, 15(6), 306-345. https://doi. org/10.17705/1jais.00364

Santos, V. dos., Bastos, R. C. (2019). Avaliação da maturidade da gestão do conhecimento na administração pública. Perspectivas em Gestão \& Conhecimento, 9(1), 24-41. http://dx.doi.org/10.21714/2236-417X2019v9n1p24

Siemsen, E., Roth, A. V., \& Balasubramanian, S. (2008). How motivation, opportunity, and ability drive knowledge sharing: The constraining-factor model. Journal of Operations Management, 26(3), 426-445. https://doi. org/10.1016/j.jom.2007.09.001

Sordi, V. F., Binotto, E., \& Ruviaro, C. F. (2014). A cooperação e o compartilhamento de conhecimentos em uma cooperativa de crédito. Perspectivas em Gestão \& Conhecimento, 4(1), 119-134. Retrieved from https:// periodicos.ufpb.br/ojs2/index.php/pgc/article/ view/16654/10830

Stewart, T. (1998). Capital intelectual: A nova vantagem competitiva das empresas. Rio de Janeiro: Editora Campus.

Takeuchi, H., \& Nonaka, I. (2008). Gestão do conhecimento. São Paulo: Bookman.

Tonet, H. C., \& Paz, M. das G. T. da. (2006). Um modelo para o compartilhamento de conhecimento no trabalho. Revista de Administração Contemporânea, 10(2), 75-94. http://dx.doi.org/10.1590/S141565552006000200005

Tracey, J. B., Tannenbaum, S. I., \& Kavanagh, M. J. (1995). Applying trained skills on the job: The importance of the work environment. Journal of Applied Psychology, 80(2), 239-252. Retrieved from http://scholarship.sha. cornell.edu/articles/883

Vaessen, M., Van Den Beemt, A., \& De Laat, M. (2014). Networked professional learning: Relating the formal and the informal. Frontline Learning Research, 2(2), 56-71. https://doi.org/10.14786/flr.v2i2.92

Van Dick, R., Grojean, M. W., Christ, O., \& Wieseke, J. (2006). Identity and the extra mile: Relationships between organizational identification and organizational citizenship behaviour. British Journal of Management, 17(4), 283-301. https://doi.org/10.1111/j.14678551.2006.00520.x

Van Knippenberg, D., Haslam, S. A., \& Platow, M. J. (2007). Unity through diversity: Value-in-diversity beliefs, work group diversity, and group identification. Group Dynamics: Theory, Research, and Practice, 11(3), 207-222. https://psycnet.apa.org/doi/10.1037/10892699.11.3.207

Venkatesh, V., \& Bala, H. (2008). Technology acceptance model 3 and a research agenda on interventions. Decision Sciences, 39(2), 273-315. https://doi.org/10.1111/ j.1540-5915.2008.00192.x

Von Krogh, G., Ichijo, K., \& Nonaka, I. (2000). Enabling knowledge creation: How to unlock the mystery of tacit knowledge and release the power of innovation. New York: Oxford University Press. 
Wachelke, J. F. R. (2013). Identificação com o grupo: Adaptação e validação de uma medida geral para o contexto brasileiro. Psicologia e Saber Social, 1(2), 187-200. https://doi.org/10.12957/psi.saber.soc.2012.4898

Wang, H., Law, K. S., Hackett, R. D., Wang, D., \& Chen, Z. X. (2005). Leader-member exchange as a mediator of the relationship between transformational leadership and followers' performance and organizational citizenship behavior. Academy of Management Journal, 48(3), 420432. https://doi.org/10.5465/amj.2005.17407908

Wang, Z., Wang, N., \& Liang, H. (2014). Knowledge sharing, intellectual capital and firm performance. Management Decision, 52(2), 230-258. https://doi.org/10.1108/ MD-02-2013-0064

\section{Autores}

\section{Valter Moreno*}

Av. Pres. Wilson, n 118, Centro, 20030-020, Rio de Janeiro, RJ , Brasil.

E-mail: valter.moreno@gmail.com

ㄴ https://orcid.org/0000-0002-1782-2401

\section{Flávia Cavazotte}

Rua Marquês de São Vicente, nº 225, Gávea, 22451-040, Rio de Janeiro, RJ , Brasil.

E-mail: flavia.cavazotte@iag.puc-rio.br

ㄴ) https://orcid.org/0000-0002-5450-3573

\section{Janicélio Pereira Dutra}

Av. Pres. Wilson, no 118, Centro, 20030-020, Rio de Janeiro, RJ , Brasil.

E-mail: janicelio@yahoo.com.br

๑ https://orcid.org/0000-0001-5821-1108

* Autor Correspondente

\section{Contribuições dos Autores}

$1^{\circ}$ autor: responsável pela concepção do estudo, elaboração do modelo, análise dos dados, e redação do artigo.

$2^{\mathbf{a}}$ autora: participou da revisão da literatura e do modelo teórico, da análise dos dados, e da redação do artigo.

$3^{\circ}$ autor: o trabalho teve por base sua dissertação de mestrado; foi responsável pela revisão da literatura e coleta dos dados; participou da redação do trabalho.
Xue, Y., Bradley, J., \& Liang, H. (2011). Team climate, empowering leadership, and knowledge sharing. Journal of Knowledge Management, 15(2), 299-312. https://doi.org/10.1108/13673271111119709

Zhang, J., Wang, Y., \& Zhang, M. Y. (2018). Team leaders matter in knowledge sharing: A cross-level analysis of the interplay between leaders' and members' goal orientations in the chinese context. Management and Organization Review, 14(4), 715-745. https://doi. org/10.1017/mor.2018.24

Zhu, Y.-Q. (2016). Solving knowledge sharing disparity: The role of team identification, organizational identification, and in-group bias. International Journal of Information Management, 36(6), 1174-1183. https://doi. org/10.1016/j.ijinfomgt.2016.08.003

\section{Financiamento}

A autora Flávia Cavazotte agradece o apoio recebido do Conselho Nacional de Desenvolvimento Científico e Tecnológico (CNPq) - Bolsa de Pesquisa 307186/2018-0 (Produtividade em Pesquisa).

\section{Conflito de Interesses}

Os autores informaram que não há conflito de interesses.

\section{Direitos Autorais}

A RAC detém os direitos autorais deste conteúdo.

\section{Verificação de Plágio}

A RAC mantém a prática de submeter todos os documentos aprovados para publicação à verificação de plágio, mediante o emprego de ferramentas específicas, e.g.: iThenticate.

\section{Método de Revisão por Pares}

Este conteúdo foi avaliado utilizando o processo de revisão por pares duplo-cego (double-blind peer-review). A divulgação das informações dos pareceristas constantes na primeira página é feita somente após a conclusão do processo avaliativo, e com o consentimento voluntário dos respectivos pareceristas.

\section{Disponibilidade dos Dados}

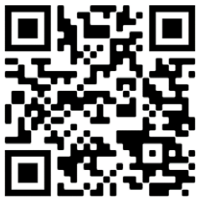

Todos os dados e materiais foram disponibilizados publicamente por meio da plataforma Mendeley e podem ser acessados em: Moreno Jr, Valter; Cavazotte, Flavia; Pereira Dutra, Janicelio (2019), "Data for: "Psycho-social and Organizational Antecedents of Knowledge Sharing in the Work Environment", published by RAC - Revista de Administração Contemporânea", Mendeley Data, v2. http://dx.doi.org/10.17632/m4bzbw3nfn.2 


\section{APENNDICE 1. ESCALAS QUE COMPUNHAM O QUESTIONÁRIO DA PESQUISA}

Itens marcados com um asterisco foram descartados na análise fatorial confirmatória (CFA) por apresentarem cargas abaixo de 0,70 ou estarem fortemente associados a variáveis latentes que não a de sua própria escala.

\section{Atitude:}

ATD1 Acredito que compartilhar conhecimentos com os outros membros do grupo de trabalho é útil para a aprendizagem de novos conhecimentos.

ATD2 Acredito que compartilhar conhecimentos com os outros membros do grupo de trabalho irá me ajudar a aprender de forma mais eficiente.

ATD3 Acredito que compartilhar conhecimentos com os outros membros do grupo de trabalho me dá a oportunidade de aprender com mais pessoas.

ATD4 Acredito que compartilhar conhecimentos com os outros membros do grupo de trabalho é útil para melhorar o meu desempenho no aprendizado.

\section{Compartilhamento de Conhecimento:}

CON1 Dedico um tempo considerável a compartilhar meus conhecimentos com os demais integrantes do grupo de trabalho no qual pertenço.

CON2 Costumo compartilhar ativamente meus conhecimentos com outros membros do grupo de trabalho que pertenço.

CON3 Costumo me envolver em discussões no meu grupo de trabalho sobre vários temas, sem me restringir a temas específicos.

CON4*Costumo responder aos comentários de outras pessoas sobre as minhas mensagens.
Entendimento Compartilhado:

ECO1 O grupo e eu concordamos no que é importante.

ECO2 O grupo e eu temos experiências similares no que tange atendimento aos clientes.

ECO3 O grupo e eu resolvemos os problemas de forma similar.

ECO4 O grupo e eu nos entendemos quando falamos. (Falamos a mesma linguagem)

ECO5 Não há dificuldades de entendimento entre o grupo e eu.

\section{Identificação com o Grupo:}

IDG1* Quando alguém critica a minha organização (ou meu grupo de trabalho), é como se estivesse me criticando pessoalmente.

IDG2* Eu tenho grande interesse em saber o que os outros pensam da minha organização (ou meu grupo de trabalho).

IDG3 Quando me refiro à organização (ou meu grupo de trabalho), eu sempre digo "nós", ao invés de "eles".

IDG4 Para mim, o sucesso desta organização (ou do grupo de trabalho que estou inserido) é como se fosse um sucesso pessoal.

IDG5 Quando alguém elogia a organização (ou meu grupo de trabalho), é como se estivesse me fazendo um elogio pessoal.

Intenção de Compartilhamento de Conhecimento:

INT1 Tenho a intenção de compartilhar minhas ideias com frequência com os outros membros do grupo de trabalho.

INT2 Sempre compartilho meus conhecimentos, a pedido de outros membros do grupo de trabalho.

INT3 Tento compartilhar as minhas experiências (educação ou formação) com os outros membros do grupo de trabalho de forma efetiva.

INT4 Tenho a intenção de compartilhar a minha forma de resolução de problemas com os outros membros do grupo de trabalho para ganhar crédito no grupo. 


\section{Liderança Transformacional:}

O meu chefe ou supervisor direto:

LTF1 Utiliza diferentes formas para me motivar.

LTF2 É um facilitador do meu trabalho.

LTF3 É acessível e receptivo às minhas opiniões, sugestões e críticas.

LTF4 Orienta-me e apoia-me nas dificuldades de trabalho.

LTF5 Diz-me claramente o que espera de mim (objetivos e responsabilidades).

LTF6 Comunica-me, periodicamente, qual é o meu desempenho no trabalho e como posso melhorá-lo.

LFT7 Atua como "orientador" quando a situação exige.

LTF8 Preocupa-se em formar/ensinar aqueles que precisam.

LTF9 Dá conselhos a quem necessita.

LTF10 Faz com que utilizemos a razão e as provas para resolver os problemas.

LTF11 Fomenta a utilização da inteligência para superar obstáculos.

LTF12 Apresenta as coisas numa perspectiva que me estimula.

LTF13 Confio na capacidade de meu chefe/ supervisor de superar qualquer obstáculo.

LTF14 Sinto orgulho de trabalhar com ele.

\section{Normas Subjetivas (Grupo):}

NSG1 Colegas de trabalho trocam informações e dicas que são úteis para melhorar sua performance no trabalho.

NSG2 Colegas de trabalho sugerem novas abordagens para resolver problemas, com base em suas próprias experiências.

NSG3 Colegas de trabalho estão abertos a novas ideias.

NSG4 Colegas de trabalho encorajam uns aos outros a usar novos conhecimentos e habilidades em suas atividades na empresa.

\section{Normas Subjetivas (Supervisores):}

NSS1 Os supervisores reconhecem e dão crédito àqueles que aplicam novos conhecimentos $\mathrm{e}$ habilidades no trabalho.

NSS2 O sistema de avaliação de desempenho da empresa associa recompensas financeiras à competência técnica dos empregados.

NSS3 O pensamento independente e inovador é encorajado pelos supervisores.

NSS4 As tarefas envolvem tempo livre para explorar novas ideias e métodos avançados que possam gerar melhorias de performance.

NSS5 Os supervisores solicitam novas ideias para resolver problemas no trabalho.

NSS6 Os supervisores constantemente expressam seu suporte para o aprendizado contínuo na empresa.

\section{Oportunidade:}

OPT1 Tenho oportunidade ao longo do dia para passar conhecimentos para meus pares.

OPT2 Minha rotina de trabalho me dá oportunidade de transferir conhecimentos para meus colegas.

OPT3 Tenho tempo suficiente para passar conhecimentos para meus colegas.

\section{Processo Formalizado:}

PFO1 Há procedimentos formais para a troca de conhecimentos na empresa.

PFO2 Os procedimentos de transferência de conhecimento da empresa são bem documentados.

PFO3 Deve-se seguir uma sequência de passos pré-definidos pela empresa quando se quer passar conhecimentos para outras pessoas.

PFO4 Minha empresa define funções, papéis e procedimentos claros para a transferência de conhecimentos entre colaboradores.

PFO5 Os procedimentos de transferência de conhecimento da empresa são amplamente divulgados para os funcionários. 